\title{
SURFACE CHEMICAL ANALYSIS OF C.I. LEUCO SULPHUR BLACK 1 DYED COTTON FABRIC AFTER-TREATED WITH PLANT-DERIVED TANNIN-BASED PROTECTIVE AGENT
}

\author{
QURATULAIN MOHTASHIM ${ }^{*}$ and MURIEL RIGOUT ${ }^{* *}$ \\ "Department of Textile Engineering, NED University of Engineering and Technology, \\ Karachi, Pakistan \\ ** School of Design, University of Leeds, Leeds, United Kingdom \\ 区orresponding author: Q. Mohtashim,qurat@neduet.edu.pk
}

Received March 2, 2021

In this investigation, the X-ray photoelectron spectroscopic technique has been used to examine the surface chemistry of C.I. Leuco Sulphur Black 1 dyed cotton fabric, which has been after-treated with a tannin-based commercial product, Bayprotect CL, and laundered in accordance with ISO 105 C06 and C09 washing protocols. The dyeings were evaluated for colour strength, wash fastness and colour loss. Surface chemical compositions of the dyeings were analysed to relate visual changes with surface chemical changes. Alterations in percentage atomic concentrations of carbon, nitrogen, oxygen and sulphur were compared for untreated, after-treated, unlaundered and laundered dyed samples. After-treated and laundered dyed samples exhibited higher content of surface sulphur and lower surface oxidation, as compared to the untreated counterparts. The $S(2 \mathrm{p})$ spectra of after-treated and laundered samples demonstrated reduced over-oxidised $\left(S^{6+}\right)$ species at $168 \mathrm{eV}$. There was 5\% and 4\% less surface oxidation for ISO 105 C06 and C09 washing systems, respectively.

Keywords: sulphur dye, XPS, wash fastness, after-treatment, tannin

\section{INTRODUCTION}

Sulphur dyes are among the most popular colourants used on cellulosic fibres and their blends, ${ }^{1}$ with wide applications on leather. ${ }^{2}$ Recent application of Chamois leather to sports garments, gloves and other personal wear and their dyeing with water-soluble sulphur dyes is also gaining attention. ${ }^{3}$ Besides, the use of solubilized sulphur dyes for colouring chrome tanned leather and tone-in-tone dyeing has also been reported recently. ${ }^{4}$ The efficacy of these dyes is further demonstrated by the extension of their application to non-cellulosic fibres, such as silk, ${ }^{5}$ nylon ${ }^{6-9}$ and wool. ${ }^{10}$

The needs of the industry are essentially satisfied owing to the promising features of sulphur dyes, namely, their adequate cost and moderate to good fastness. However, the use of these dyes is gradually declining because of the environmental hazards produced by the use of the conventional reducing agent - sodium sulphide, and the dyes' low resistance to oxidation during laundering with detergent and perborate/peroxide formulations.

In spite of having certain practical limitations, efforts have been made to replace sodium sulphide with environment-friendly alternatives, such as the use of various reducing sugars, ${ }^{11-13}$ enzymes $^{14-16}$ and electrochemical reduction ${ }^{17,18}$ methods have been investigated. However, for improving the wet fastness of sulphur dyeings by exhaust and continuous after-treatment methods, cationic fixing agents, ${ }^{19-21}$ lanthanides ${ }^{22}$ and crease resistant finishes ${ }^{23}$ have been reported. Moreover, sequential application of cationic polymers/reactants, tannins and crease resistant finishes have been found to improve the resistance of the dyeings to ISO $105 \mathrm{C06}$ and ISO 105 C09 washing. $^{24-28}$

Tannins are naturally occurring water-soluble polyphenolic compounds of high molecular weight, consisting of phenolic hydroxyl groups, which enable them to crosslink with proteins and 
other macromolecules. Tannins include a large class of organic substances having different chemical compositions and reactions..$^{29,30}$ Bayprotect CL (BPCL) is an anionic tannin-based protective stain-release agent for polyamide 6,6 and polyamide 6 , and acts as an antioxidant, providing protection against cleaning agents, chlorine-based bleaches, in particular, hypochlorite, and other oxidative substances, such as benzoyl peroxide ("Tanatex Chemicals Product datasheet"). It is a yellowish brown viscous liquid and can be diluted with water at any ratio. Its general application is on polyamide and the best results are obtained on this fibre when tested against oxidative substances. It is stable to substances causing hardness of water, dilute organic and inorganic acids, but has only limited stability to heavy metal salts and alkalis. It is a proprietary formulation, hence the exact chemistry of the product is unknown.

The development of techniques for the surface selective modification of cotton fibres and the need to understand the changes in the fibre chemistry and properties has emphasised the necessity for the application of the XPS (X-ray photoelectron spectroscopy) technique in textiles. In order to study the chemistry of modified cotton, the introduction of the XPS method was pioneered by Soignet. ${ }^{32}$ Recently, Mohtashim et $a l$. have studied the effects of after-treatment with cationic fixing agents on the surface chemistry of Sulphur Black 1 dyed cotton fabric. ${ }^{33}$ The use of tannin-based BPCL as a protective agent for sulphur dyeings has been examined elsewhere, ${ }^{25}$ where visual colour changes have been described. However, the surface chemistry of the aftertreated samples has not yet been explored. In the present study, the relative effect of aftertreatments with BPCL on ISO 105 C06 and ISO 105 C09 washing of C.I. Leuco Sulphur Black 1 dyed cotton fabric has been evaluated to compare visual changes with surface chemical changes. The chemical and physical effects of the aftertreatment with BPCL on the outer surface of C.I. Leuco Sulphur Black 1 dyed fabrics have been investigated for the first time. The surface sensitive X-ray photoelectron spectroscopic technique was used to examine the outer surface (3-10 nm) of the sulphur dyed cotton fabric. This spectroscopic technique helped in understanding the nature of the fibre surface interface of untreated and after-treated dyeings upon exposure to chemically aggressive bleaching media and the improvements produced as a result of after- treatments. It also helped to study the effect of the after-treatment on the durability of the dye and characterize elemental composition and surface functionalities.

\section{EXPERIMENTAL}

\section{Materials}

A plain woven, bleached, $100 \%$ cotton fabric, 103 $\mathrm{g} / \mathrm{m}^{2}$, supplied by Phoenix Calico Ltd., UK, was used throughout this study and dyed with 5\% o.w.f. (on weight of fabric) C.I. Sulphur Black 1. ECE nonphosphate detergent, ECE phosphate detergent and tetraace tylethylenediamine (TAED, 92\% active) were purchased from the Society of Dyers and Colourists (SDC), Bradford, UK. Sodium perborate tetrahydrate (97\% active, laboratory grade, Aldrich Chemicals Ltd., UK) was purchased from Aldrich Chemicals Ltd., UK. Diresul Reducing agent D (RAD), a glucose-based biodegradable reducing agent by Clariant was used as a reductant. The oxidation bath comprised hydrogen peroxide and soda ash (laboratory grade, Aldrich Chemicals Ltd., UK). The fabric was soaped with a non-ionic detergent. The tannin-based product BPCL was kindly supplied from Tanatex Chemicals B.V., Netherlands, and is a proprietary formulation.

\section{Dyeing}

All dyeings were carried out in $1000 \mathrm{~cm}^{3}$ capacity sealed stainless steel dye pots in a Mathis Labomat laboratory dyeing machine. Dyeing of cotton with Diresul RAD was performed by the method prescribed by Clariant (Fig. 1). The cotton fabric was introduced into a dye bath containing $5 \%$ on o.w.f. (on weight of fabric) Diresul C.I. Leuco Sulphur Black 1 dye liquid, $25 \mathrm{~g} / \mathrm{L}$ sodium chloride, $13 \mathrm{~mL} / \mathrm{L}$ sodium hydroxide $\left(67^{\circ} \mathrm{Tw}\right), 9 \mathrm{~g} / \mathrm{L}$ Diresul RAD with a liquor to goods ratio of $10: 1$. The dye bath was raised to $98{ }^{\circ} \mathrm{C}$, at a gradient of $4{ }^{\circ} \mathrm{C} / \mathrm{min}$, and maintained at the boil for 60 minutes. The solution was then cooled to $50{ }^{\circ} \mathrm{C}$ and the fabric was removed. The dyed fabrics were then washed thoroughly with cold water to remove any unfixed surface dye and then oxidised with $5 \mathrm{~g} / \mathrm{L}$ hydrogen peroxide and $1 \mathrm{~g} / \mathrm{L}$ soda ash at $40-45{ }^{\circ} \mathrm{C}$ for 15 minutes. The fabric was then soaped with $1 \mathrm{~g} / \mathrm{L}$ of non-ionic detergent at the boil for 20 minutes and finally rinsed with warm and cold water and air dried. The liquor to goods ratio employed for oxidation and soaping was 10:1.

\section{After-treatment with BPCL}

Aqueous treatment baths containing 4\% o.m.f. BPCL and $100 \mathrm{~g} / \mathrm{L}$ sodium sulphate were prepared and adjusted to $\mathrm{pH} 3.4$ with citric acid. The liquor to goods ratio of the treatment bath was adjusted to 10:1. Cotton fabrics, pre-dyed with the sulphur dye (5\% o.m.f.), were added to the treatment baths at $20{ }^{\circ} \mathrm{C}$ and the temperature of the bath was then raised to $80{ }^{\circ} \mathrm{C}$ at 4 ${ }^{\circ} \mathrm{C} / \mathrm{min}$. After treating for 20 minutes, the finished 
fabrics were removed, rinsed with warm water, then with cold water, and finally allowed to dry at room

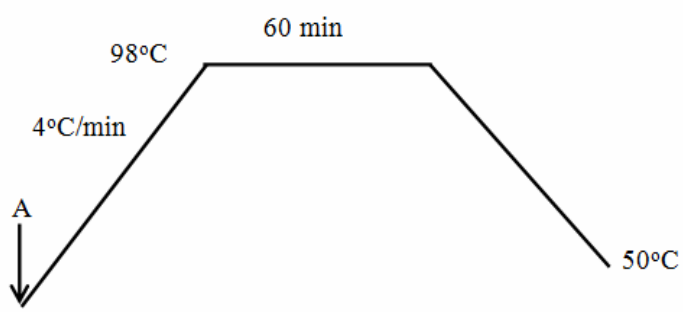

Figure 1: Sulphur dyeing method for cotton using Diresul RAD; A - dyebath contains fabric, dyestuff, sodium chloride, sodium hydroxide, Diresul RAD and water)

\section{Determination of fastness properties}

The colour fastness of the untreated and aftertreated sulphur dyed fabrics was tested according to ISO standard methods, including fastness to washing (ISO 105 C06/C2S and ISO 105 C09).

\section{Colour measurement}

The colorimetric data of the dyed and after-treated cotton fabrics were measured using a Datacolor Spectroflash 600 spectrophotometer, with a $10^{\circ}$ standard observer and D65 illuminant, and were the average of four measurements. The colour strength $(\mathrm{K} / \mathrm{S})$ was evaluated using the Kubelka-Munk equation (represented in Scheme 1).

$$
\left(\frac{K}{s}\right)_{\lambda}=\frac{\left(1-R_{R}\right)^{2}}{2 R_{\lambda}}
$$

where $\mathrm{K}$ is the absorption coefficient, $\mathrm{S}$ is the scatter coefficient, $\mathrm{R}$ is the reflectance expressed as a fractional value at wavelength of maximum absorption $\lambda$.

The $\%$ colour loss of the untreated and after-treated dyed fabrics after laundering was determined with the following equation (Scheme 2):

$\%$ colour loss $=\frac{\frac{\mathrm{K}}{\mathrm{S}} \text { before washing }-\frac{\mathrm{K}}{\mathrm{S}} \text { after washing }}{\frac{\mathrm{K}}{\mathrm{S}} \text { before washing }} \times 100$

\section{XPS measurements}

XPS analysis was performed using a Kratos Axis system spectrometer. The fabric samples $(5 \mathrm{~mm} \times 5$ $\mathrm{mm}$ ) were cut from the centre of the specimen and attached to the sample holder using a double sided tape of the same size. The samples were irradiated with monochromatic Al $\mathrm{K}_{\alpha}$ X-rays $(1486.6 \mathrm{eV})$, with a power of $150 \mathrm{~W}$. The wide scan spectra were recorded with pass energy of $160 \mathrm{eV}$, from which the surface composition $(\mathrm{C}, \mathrm{O}, \mathrm{S}$ and $\mathrm{N})$ was determined. High resolution Carbon (1s), Nitrogen (1s) and Sulphur (2p) spectra were recorded with pass energy of $40 \mathrm{eV}$ and the binding energy (BE) values were calculated relative to the Carbon (1s) photoelectron peak at 285.0 $\mathrm{eV}$. Charge compensation for the samples was temperature (Fig. 2).

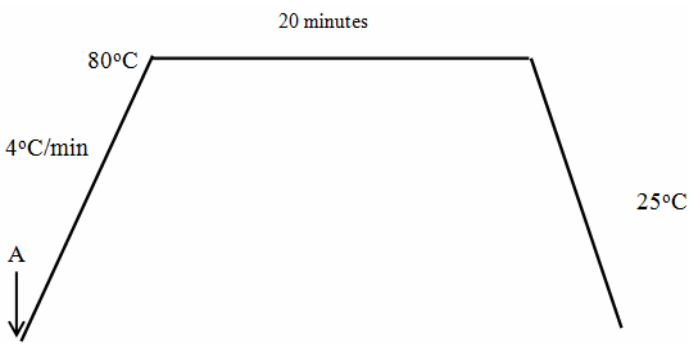

Figure 2: After-treatment with Bayprotect $\mathrm{Cl}$ (exhaust application); A - finishing bath contains dyed fabric, $4 \%$ o.w.f. Bayprotect $\mathrm{Cl}, 100 \mathrm{~g} / \mathrm{L}$ sodium sulphate, citric acid to $\mathrm{pH} 3.4$

achieved using a 4-7 eV beam at a flood current of approximately $0.1 \mathrm{~mA}$, with an electrically ground 90\% transmission nickel mesh screen. All samples were analysed in duplicate and data were analysed using the CASA XPS software. ${ }^{34}$

\section{RESULTS AND DISCUSSION \\ Investigation into the effects of after- treatments with BPCL on elemental compositions of C.I. Leuco Sulphur Black 1 dyed fabric}

X-ray photoelectron spectroscopic measurements of untreated sulphur black dyed cotton fabric, in comparison with BPCL aftertreated samples, were made to analyse the surface chemistry of the untreated and after-treated dyeings before and after laundering. The colorimetric data in Table 1 show that the aftertreatment with the tannin-based product increases the resistance of the dyed fabric to the oxidative bleaching action of the laundering formulations. It improves the grey scale rating of the laundered samples by half a unit for ISO 105 C06 and ISO 105 C09 washing regimes, respectively. Similar results were reflected through the $\%$ colour loss data, showing a reduction of $7 \%$ and $12 \%$ for after-treated laundered dyeings for ISO 105 C06 and ISO 105 C09 washings, respectively.

Table 2 details the elemental compositions of unlaundered and laundered samples of dyed and BPCL after-treated fabrics subjected to ISO 105 C06 and ISO 105 C09 washings. On analysing unlaundered samples (samples 1 and 4), treating the dyed fabric with BPCL shows a slight reduction in sulphur and carbon content, which probably have arisen as a result of the removal of surface dye and slight fibrillation due to the aftertreatments. An increase in oxygen content 


\section{QURATULAIN MOHTASHIM and MURIEL RIGOUT}

describes the functionalization of the surface with oxygen-containing groups, however, the nitrogen content remains unchanged. The chemistry of BPCL does not refer to the presence of nitrogen, which is further supported by the XPS surface elemental composition. Hence, this suggests that the tannin-based product BPCL does not introduce any nitrogen species on the dyed fabric.

Examining the laundered samples, the untreated sulphur dyed fabric undergoes a concomitant reduction in sulphur content from $1.2 \%$ (sample 1) to $0.8 \%$ (sample 2) and $0.5 \%$ (sample 3) for ISO 105 C06 and ISO 105 C09 washing, respectively. This suggests the oxidation of the dye disulphide bonds, leading to the formation of water-soluble sulphonated short chain dye fragments, which are lost into solution. ${ }^{35}$ As the sulphur content in sample 3 is less than in sample 2, this means that the effect of ISO $105 \mathrm{C} 09$ is far more destructive than that of ISO 105 C06 washing, owing to the presence of a high concentration of bleaching agent (sodium perborate) and TAED in the wash liquor.

However, BPCL after-treated samples laundered with ISO 105 C06 and ISO 105 C09 washing showed increased sulphur concentrations of $1 \%$ (sample 5) and $0.6 \%$ (sample 6), respectively, which is much higher than the percentage content of surface sulphur found on the untreated samples. This indicates that, as a result of the after-treatments, the sulphur species were bound to the fabric surface and retained there even after laundering. Inspecting the nitrogen contents, it was observed that the untreated and ISO 105 C09 laundered sample showed a relative decrease in surface nitrogen concentrations from $1.1 \%$ (sample 1) to $0.9 \%$ (sample 3), while ISO 105 C06 washing did not affect the surface nitrogen content (sample 2). This slight reduction in nitrogen content might be expected due to the removal of dye. However, BPCL after-treated dyeings significantly lose surface nitrogen on laundering (samples 5 and 6).

Table 1

Colorimetric data for C.I. Leuco Sulphur Black 1 dyed fabric after-treated with Bayprotect CL, following ISO 105 C06 and ISO 105 C09 washing

\begin{tabular}{lccccc}
\hline Dyed fabric samples & $\begin{array}{c}\text { Washing } \\
\text { treatment }\end{array}$ & L* & K/S & $\begin{array}{c}\text { \% Colour } \\
\text { loss }\end{array}$ & $\begin{array}{c}\text { Change in shade } \\
\text { (Grey scale rating) }\end{array}$ \\
\hline \multicolumn{7}{c}{ Untreated } \\
\hline Sample 1 & None & 27.5 & 9.3 & - & - \\
Sample 2 & WF 1 & 29.0 & 8.6 & 8 & 4 \\
Sample 3 & WF 2 & 40.7 & 3.7 & 60 & 1 \\
\hline \multicolumn{7}{c}{ After-treated } \\
Sample 4 & None & 29.0 & 8.6 & - & - \\
Sample 5 & WF 1 & 28.6 & 8.5 & 1 & $4 / 5$ \\
Sample 6 & WF 2 & 43.2 & 4.5 & 48 & $1 / 2$ \\
\hline
\end{tabular}

Note: WF 1: ISO 105 C06; WF 2: ISO 105 C09; Sample 1: Untreated sulphur dyed fabric; Sample 2: Untreated sulphur dyed fabric laundered with ISO 105 C06; Sample 3: Untreated sulphur dyed fabric laundered with ISO 105 C09; Sample 4: Sulphur dyed and BPCL after-treated fabric; Sample 5: Sulphur dyed and BPCL after-treated fabric laundered with ISO 105 C06; Sample 6: Sulphur dyed and BPCL after-treated fabric laundered with ISO 105 C09

Table 2

XPS surface elemental composition for C.I. Leuco Sulphur Black 1 dyed fabric after-treated with Bayprotect CL, following ISO 105 C06 and ISO 105 C09 washing

\begin{tabular}{lccccc}
\hline \multirow{2}{*}{ Dyed fabric samples } & Washing & \multicolumn{4}{c}{ \% Atomic composition } \\
\cline { 3 - 5 } & treatment & Carbon & Nitrogen & Oxygen & Sulphur \\
\hline Sample 1 & None & 70.5 & 1.1 & 27.2 & 1.2 \\
Sample 2 & WF 1 & 70.6 & 1.1 & 27.5 & 0.8 \\
Sample 3 & WF 2 & 70.7 & 0.9 & 27.9 & 0.5 \\
\hline \multicolumn{5}{r}{ After-treated } \\
\hline Sample 4 & None & 70.1 & 1.1 & 27.7 & 1.1 \\
Sample 5 & WF 1 & 70.0 & 0.9 & 28.1 & 1.0 \\
Sample 6 & WF 2 & 69.3 & 0.7 & 29.4 & 0.6 \\
\hline
\end{tabular}


Also, a comparative increase in the oxygen content was observed for laundered samples, which indicates surface oxidation as a result of oxidative bleaching environment offered by sodium perborate/detergent washing.

Investigation into the effects of aftertreatments with BPCL on S (2p) spectra of C.I. Leuco Sulphur Black 1 dyed fabric

Examination of the $S(2 p)$ spectra of sulphur dyed cotton fabric indicates the presence of sulphur at the surface of the cotton fibres and details the different oxidation states of sulphur. As illustrated in Table 3, all the samples exhibit broad sulphur signals and well-separated peak structures at low $(164 \mathrm{eV})$ and high $(168 \mathrm{eV})$ binding energies.

In the case of untreated and unlaundered sulphur dyed fabric (sample 1, Fig. 3), a distinctive peak can be seen at $168 \mathrm{eV}$, contributing around $48 \%$ of the total sulphur content. This peak intensity proposes the reoxidation of the alkali reduced sulphur dye thiols to reform the insoluble disulphide bond-based sulphur dye, resulting in over-oxidation to $S^{6+}$ species. ${ }^{35}$ The presence of oxidised species could possibly be related to the slight over-oxidation caused by the use of hydrogen peroxide in the final dyeing stage for converting the thiol derivative into the parent insoluble form of the dye, which is the over-oxidation of the disulphide groups forming ionisable sulpho groups caused by active peroxide. ${ }^{2}$ The effect of laundering with detergent, sodium perborate and TAED was to increase the amount of higher binding energy spectral component at $168 \mathrm{eV}$ due to oxidation. As shown in Table 3 (samples 2 and 3), the peak areas at $168 \mathrm{eV}$ increase from $40 \%$ for the unlaundered to $70 \%$ and $89 \%$ for ISO I05 C06 and ISO I05 C09 laundered ones, respectively (Figs. 4 and 5). Most likely, the precursor to the loss of the dye from the fibre surface is the $S^{6+}$ oxidised dye derivative, which may be assigned to $-\mathrm{SO}_{3}^{-},-\mathrm{S}-\mathrm{SO}_{2}^{-}$or $-\mathrm{S}-\mathrm{SO}_{3}^{-}$species. ${ }^{35}$

Table 3

Relative intensity data of the deconvoluted S (2p) spectra for C.I. Leuco Sulphur Black 1 dyed fabric after-treated with Bayprotect Cl, following ISO 105 CO6 and ISO 105 C09 washing

\begin{tabular}{|c|c|c|c|}
\hline \multirow{2}{*}{ Dyed fabric samples } & \multirow{2}{*}{ Washing treatment } & \multicolumn{2}{|c|}{ Peak areas (\%) } \\
\hline & & $164 \mathrm{eV}$ & $168 \mathrm{eV}$ \\
\hline \multicolumn{4}{|c|}{ Untreated } \\
\hline Sample 1 & None & 52 & 48 \\
\hline Sample 2 & WF 1 & 30 & 70 \\
\hline Sample 3 & WF 2 & 11 & 89 \\
\hline \multicolumn{4}{|c|}{ After-treated } \\
\hline Sample 4 & None & 51 & 49 \\
\hline Sample 5 & WF 1 & 35 & 65 \\
\hline Sample 6 & WF 2 & 15 & 85 \\
\hline
\end{tabular}

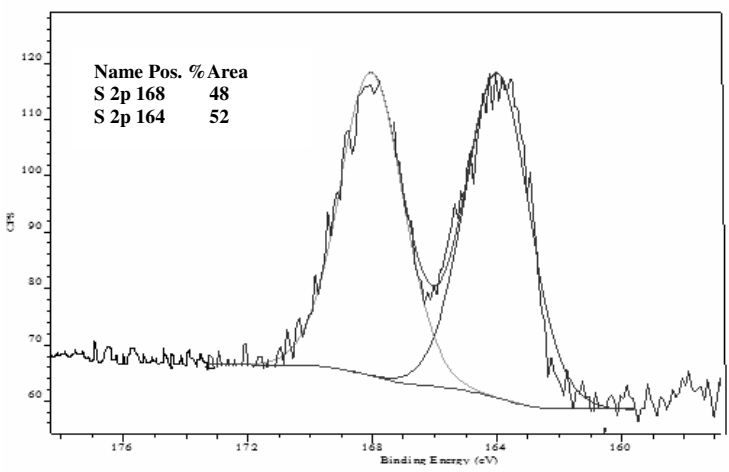

Figure 3: S (2p) spectrum of untreated C.I. Leuco Sulphur Black 1 dyed fabric (unlaundered) 


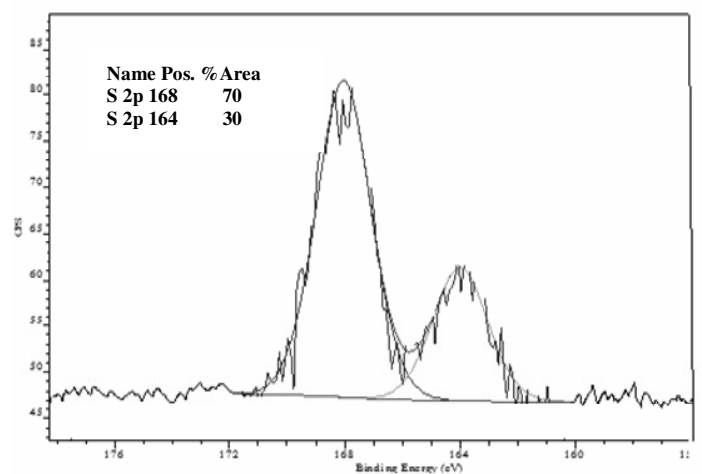

Figure 4: S (2p) spectrum of untreated C.I. Leuco Sulphur Black 1 dyed fabric (ISO 105 C06 laundered)

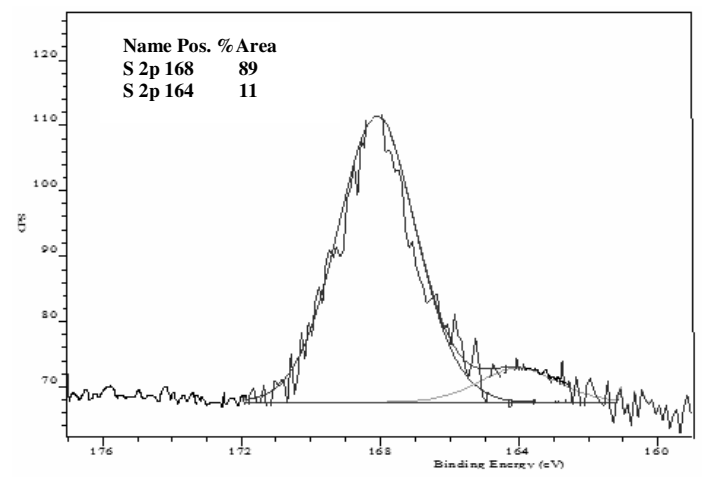

Figure 5: S (2p) spectrum of untreated C.I. Leuco Sulphur Black 1 dyed fabric (ISO 105 C09 laundered)

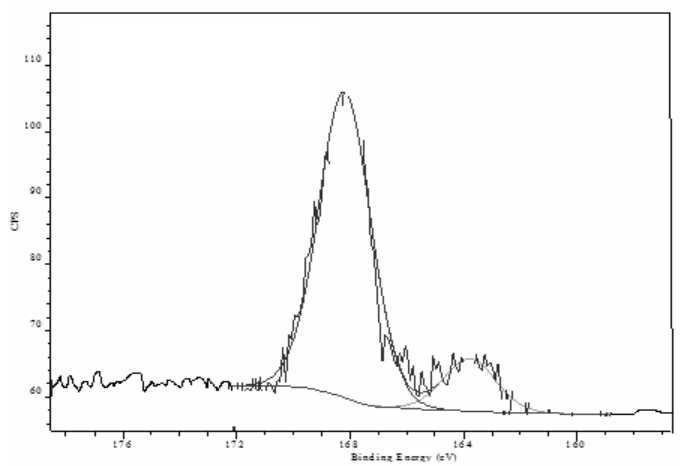

Figure 6: S (2p) spectrum of C.I. Leuco Sulphur Black 1 dyed fabric after-treated with 4\% o.w.f. Bayprotect Cl (ISO 105 C09 laundered)

It was observed that dyed fabric after-treated with BPCL (sample 4) also gives rise to the formation of two peaks at $164 \mathrm{eV}$ and $168 \mathrm{eV}$, which correspond to unoxidised $\left(\mathrm{S}^{2+}\right)$ and overoxidised $\left(S^{6+}\right)$ species, respectively, with a slight increase in the oxidised species. This explains that the treatment of the dyed fabric with BPCL causes minor oxidation. Examination of the $S(2 p)$ spectra of after-treated laundered samples 5 and 6 mirrored a low level of oxidation and minimal loss of sulphur observed for the comparable laundered untreated counterparts. The $S(2 p)$ spectra of laundered samples 5 and 6 illustrate a concomitant reduction in over-oxidised $\left(\mathrm{S}^{6+}\right)$ species at $168 \mathrm{eV}$. The observed reduction is from $70 \%$ to $65 \%$ for ISO $105 \mathrm{C} 06$ and from $89 \%$ to $85 \%$ for ISO $105 \mathrm{C} 09$ washing systems. The S (2p) spectrum of the after-treated and ISO 105 C09 laundered sample is shown in Figure 6.

The S (2p) XP spectra for untreated and BPCL treated samples were analysed to differentiate the possible presence of three main sulphur species, namely, unoxidised $\mathrm{S}^{2+}$ (-S-, $-\mathrm{S}-\mathrm{S}$-), over-oxidised $\mathrm{S}^{6+}\left(-\mathrm{SO}_{3}^{-}, \quad-\mathrm{S}-\mathrm{SO}_{2}^{-}\right.$or $\left.-\mathrm{S}-\mathrm{SO}_{3}^{-}\right)$and partially or intermediate oxidised $\left(\mathrm{S}^{4+}\right)$. However, the presence of partially oxidised species could not be identified.

Investigations into the effects of aftertreatments with BPCL on C (1s) spectra of C.I. Leuco Sulphur Black 1 dyed fabric

Relative amounts of carbon with different numbers of oxygen bonds were estimated from the high resolution $\mathrm{C}$ (1s) carbon spectra. Concentrations of carbon functionalities obtained from deconvoluted carbon spectra for untreated and treated samples are summarised in Figure 7. The carbon compound classification was based on the number of oxygen bonds attached to the carbon atoms: the peaks at $285.0 \mathrm{eV}(\mathrm{C} 1), 286.6$ $\mathrm{eV}(\mathrm{C} 2), 288.2 \mathrm{eV}(\mathrm{C} 3)$ and $289.4 \mathrm{eV}(\mathrm{C} 4)$ are due to carbons with $0,1,2$ or 3 bonds to oxygen respectively. ${ }^{36}$

Examination of the high resolution $\mathrm{C}$ (1s) spectrum of untreated and unlaundered sulphur dyed fabric (Fig. 8), against ISO 105 C06 laundered fabric (Fig. 9), indicated a fall in hydrocarbon signal intensity at $285 \mathrm{eV}(11 \%)$, and a rise in the oxidised species at $286.6 \mathrm{eV}$ (2\%), $288.0 \mathrm{eV}(29 \%)$ and $289.0 \mathrm{eV}(34 \%)$. 
Meanwhile, the high resolution carbon spectrum of untreated fabric laundered with ISO 105 C09 portrays a significant rise in oxidised species intensities at $286.6 \mathrm{eV}(24 \%), 288.0 \mathrm{eV}(>100 \%)$ and $289.0 \mathrm{eV}(>100 \%)$. Presumably, this change was due to a concomitant loss in surface hydrocarbon residue and some oxidation of the cellulosic backbone.

For samples treated with BPCL, deconvolution analysis showed an increase of oxygen-based functional groups, such as $\mathrm{C}-\mathrm{O}(286.6 \mathrm{eV}), \mathrm{C}=\mathrm{O}$ $(288 \mathrm{eV})$ and $\mathrm{O}=\mathrm{C}-\mathrm{O}(289 \mathrm{eV})$, as shown in sample 4. This is in good agreement with the slight oxidation observed in Table 2, portraying an increase in the oxygen content of the aftertreated sample. The relative amount of each type of carbon was modified, which can be observed in peak intensity changes in Figure 7 (a), where the carbon $\mathrm{C} 2, \mathrm{C} 3$ and $\mathrm{C} 4$ peak areas were significantly increased, compared to untreated dyed fabric. These results imply that the surface of the sulphur dyed cotton fabric became partially oxidised by fixative exposure, resulting in a decrease of $\mathrm{C}-\mathrm{C} / \mathrm{C}-\mathrm{H}$ bonds, and a significant increase of oxidised species, although it must be noted that BPCL itself is known to contain carbonyl and carboxylic acid species.
However, on treating the fabric with BPCL and exposing it to ISO 105 C06 washing, an associated decrease in $\mathrm{C} 1(14 \%)$ and an increase in C2 (1\%), C3 (25\%) and C4 (31\%) components, with respect to sample 4, were observed (Fig. 7 (b)). This percentage increase in oxygen containing functional groups is lesser than in the untreated laundered fabric (sample 2).

However, on exposing the after-treated fabric to ISO $105 \mathrm{C} 09$ washing, an increase in $\mathrm{C} 1$ and a decrease in $\mathrm{C} 2, \mathrm{C} 3$ and $\mathrm{C} 4$ components were detected. Compared to sample 4, the non-oxidised carbon fraction $(\mathrm{C} 1)$ in BPCL treated fabric (sample 4) has increased significantly (26\%), whereas the carbon with oxygen-based functional groups $(\mathrm{C} 2, \mathrm{C} 3$ and $\mathrm{C} 4)$ was dramatically reduced, that is $10 \%, 18 \%$ and $60 \%$, respectively. The chemical composition of the after-treated and ISO 105 C09 laundered fabric suggests that the after-treatment with BPCL reduces the formation of oxidised functionalities and contributes to the formation of carbon compounds without neighbouring oxygen $(\mathrm{C}-\mathrm{C}, \mathrm{C}-\mathrm{H})$. It is therefore proposed that BPCL may have a protecting effect and partially prevent the oxidation of sulphur dyed cotton fabric.

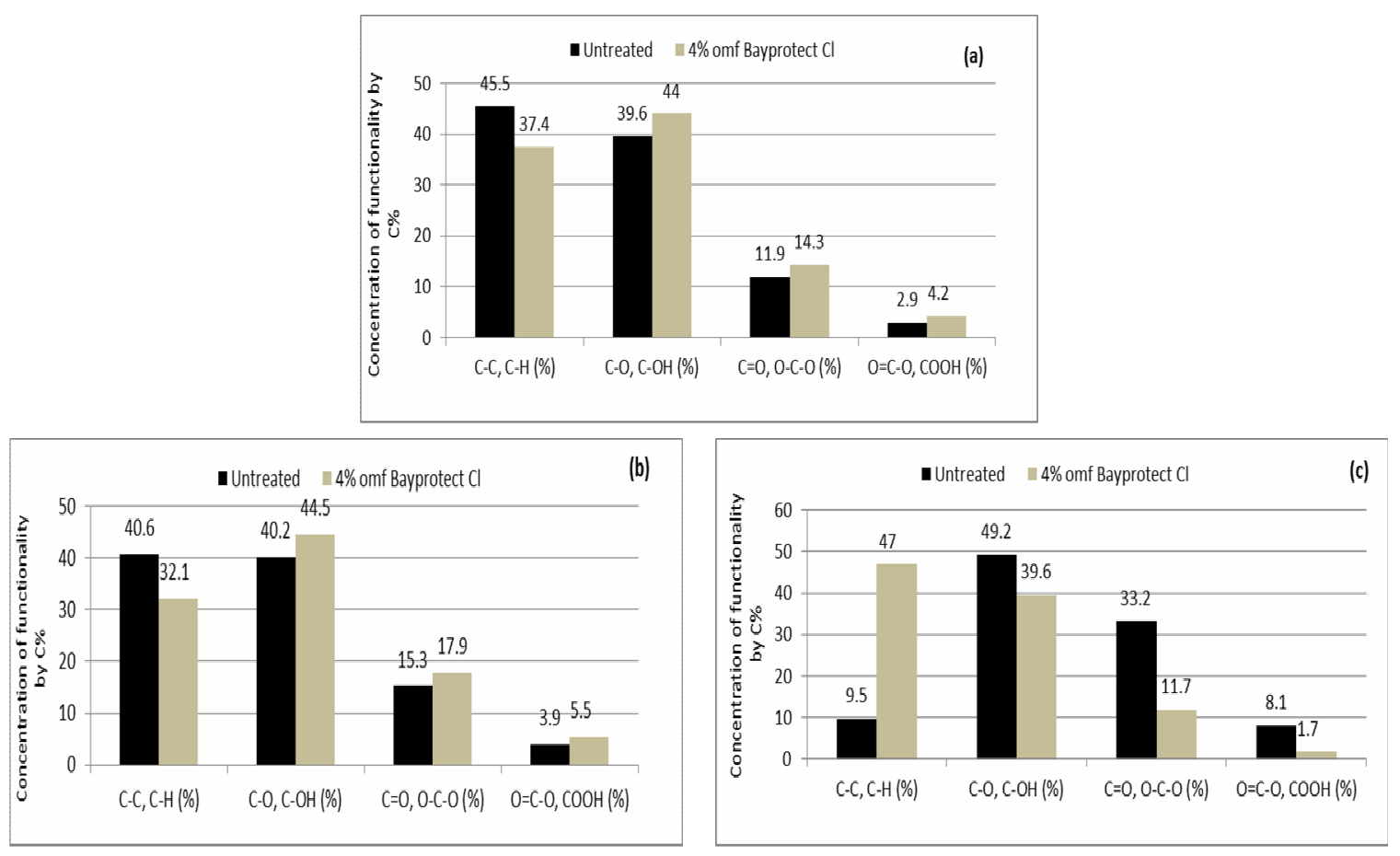

Figure 7: Concentration of carbon functionalities determined by curve fitting of the $\mathrm{C}$ (1s) peaks from XPS spectra (fabric dyed with C.I. Leuco Sulphur Black 1 and after-treated with Bayprotect $\mathrm{Cl}$ ): a) before laundering, b) after laundering with ISO 105 C06, c) after laundering with ISO 105 C09 


\section{QURATULAIN MOHTASHIM and MURIEL RIGOUT}

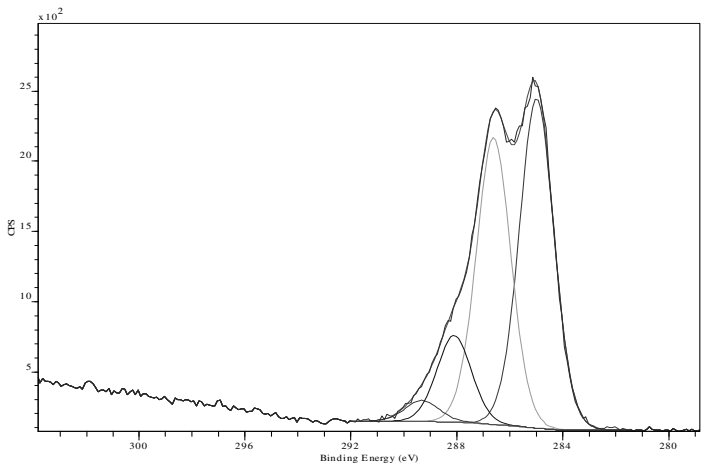

Figure 8: C (1s) spectrum of untreated C.I. Leuco Sulphur Black 1 dyed fabric (unlaundered)

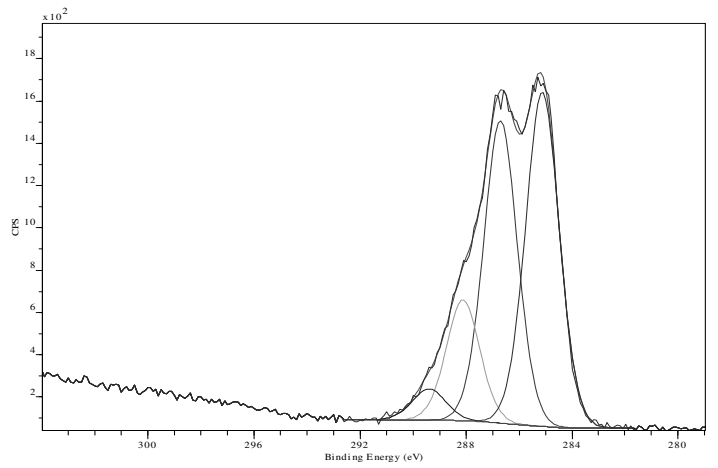

Figure 9: C (1s) spectrum of untreated C.I. Leuco Sulphur Black 1 dyed fabric (ISO 105 C06 laundered)

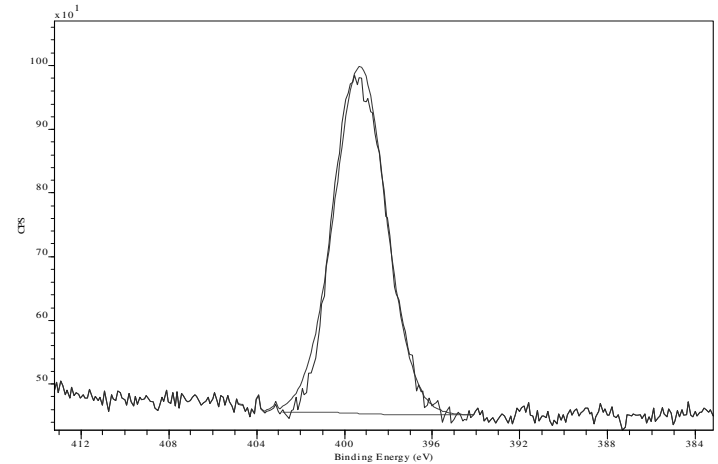

Figure 10: N (1s) spectrum of C.I. Leuco Sulphur Black 1 dyed fabric

\section{Investigations into the effects of after- treatments with BPCL on N (1s) spectra of C.I. Leuco Sulphur Black 1 dyed fabric}

The N (1s) spectra of all the samples presented a peak at $398 \mathrm{eV}$ (Fig. 10). The nitrogen content in sulphur dyed cotton is highlighted in Table 2, which shows the presence of nitrogen based proteins, pectins and waxes, which are usually associated with cotton (sample 1). Fabric aftertreated with BPCL exhibits the same nitrogen content as untreated fabric, this is because the chemistry of BPCL does not correspond to the presence of nitrogen species.

\section{CONCLUSION}

The effects of after-treatments with BPCL on wash fastness of C.I. Leuco Sulphur Black 1 have been evaluated with the help of the surface sensitive XPS technique. High resolution spectra of sulphur, carbon and nitrogen were analysed to demonstrate improvements in the wash fastness of the samples treated with the tannin-based commercial product. A significant increase in surface sulphur concentration and a reduced percentage area of oxidised species $\mathrm{S}^{6+}$ at $168 \mathrm{eV}$ were observed for the after-treated sample laundered with ISO 105 C06 and C09 washing systems. In addition, the examination of $\mathrm{C}(1 \mathrm{~s})$ spectra of after-treated and laundered samples revealed reduced concentrations of oxidised carbon species ( $\mathrm{C} 2, \mathrm{C} 3$ and $\mathrm{C} 4)$. The detailed examinations of high resolution $C(1 s)$ and $S(2 p)$ spectra of untreated, after-treated, unlaundered and laundered samples indicate that BPCL tends to protect C.I. Leuco Sulphur Black 1 dyed fabric against the oxidative bleaching action of ISO 105 C06 and ISO 105 C09 washing regimes.

ACKNOWLEDGMENTS: Quratulain Mohtashim would like to thank the Department of Textile Engineering, NED University of Engineering and Technology, for providing technical facilities to fulfill the requirements of the experimental work. The author also acknowledges financial support in terms of a PhD scholarship from NED University of Engineering and Technology, Pakistan, through Higher Education Commission to carry out this study at the School of Materials, The University of Manchester, UK.

\section{REFERENCES}

A. D. Broadbent, "Basic Principles of Textile Coloration", Society of Dyers and Colorists, Bradford, 
2001, pp. 379-387

2 J. Shore, "Cellulosics Dyeing", Society of Dyers and Colourists, Bradford, 1995, pp. 280-319

A. Jaya Prakash, R. Aravindhan, N. Nishad Fathimaa and J. Raghava Rao, J. Am. Leather Chem. Assoc., 111, 383 (2016)

4 R. Venba, M. Jawahan, G. Jothi, D. Dakshinamoorthy, N. C. Babu et al., J. Am. Leather Chem. Assoc., 110, 177 (2015)

5 S. M. Burkinshaw and M. Paraskevas, Dyes Pigm., 87, 225 (2010),

https://doi.org/10.1016/j.dyepig.2010.03.031

6 S. M. Burkinshaw, S. N. Chevli and D. J. Marfell,

Dyes Pigm., $\quad 45, \quad 65 \quad$ (2000), https://doi.org/10.1016/s0143-7208(00)00003-6

7 S. M. Burkinshaw, K. Lagonika and D. J. Marfell, Dyes Pigm., $\quad$ 58, $157 \quad$ (2003), https://doi.org/10.1016/s0143-7208(03)00051-2

8 S. M. Burkinshaw, K. Lagonika and D. J. Marfell, Dyes Pigm., 56, $251 \quad$ (2003), https://doi.org/10.1016/s0143-7208(02)00146-8

9 S. M. Burkinshaw and K. Lagonika, Dyes Pigm., 69 , 185

(2006),

https://doi.org/10.1016/j.dyepig.2005.03.012

10 J. Y. Cai, J. A. Rippon, J. McDonnell and A. E. Parnell, Color. Technol., 128, 9 (2012), https://doi.org/10.1111/j.1478-4408.2011.00333.x

11 A. Madhu, G. Singh, A. Sodhi, S. Malik and Y. Madotra, J. Text. Apparel, Technol. Manag., 7, 1 (2012)

12 R. Zouhaier, D. Sofiène and S. Faouzi, Eur. Sci. J., 10, 436 (2014)

13 A. Baffoun, M. Hamdaoui and Z. Romdhani, Indian J. Fibre Text. Res., 40, 57 (2015)

14 P. Jaruhar and J. N. Chakraborty, Text. Res. J., 83, 1345

(2013),

https://doi.org/10.1177/0040517512461703

15 J. N. Chakrabortya and P. Jaruhar, Indian J. Fibre Text. Res., 39, 303 (2014)

16 P. Jaruhar and J. N. Chakraborty, J. Chem. Chem. Eng., 7, 930 (2013)

17 T. Bechtold, E. Burtscher and A. Turcanu, Text. Chem. Color., 30, 72 (1998)

18 T. Bechtold, A. Turcanu and W. Schrott, J. Appl.

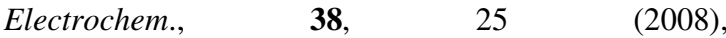
https://doi.org/10.1007/s10800-007-9390-5

19 S. M. Burkinshaw, F. E. Chaccour and A.
Gotsopoulos, Dyes Pigm., 34, 227 (1997), https://doi.org/10.1016/s0143-7208(96)00075-7

20 S. M. Burkinshaw and G. W. Collins, Dyes Pigm., 29, 323 (1995), https://doi.org/10.1016/01437208(95)00058-5

21 S. M. Burkinshaw and G. W. Collins, J. Soc. Dye. Colour., 114, 12 (1998), https://doi.org/10.1111/j.1478-4408.1998.tb01914

22 W. Zhou and Y. Yang, Ind. Eng. Chem. Res., 49, 4720 (2010), https://doi.org/10.1021/ie901901r

23 S. M. Burkinshaw and G. W. Collins, Dyes Pigm., 33, 1 (1997), https://doi.org/10.1016/s01437208(96)00035-6

24 Q. Mohtashim, M. Rigout and C. M. Carr, Color. Technol, $\quad$ 136, 263 (2020), https://doi.org/10.1111/cote. 12460

25 P. J. Broadbent, Q. Mohtashim, M. Rigout and C. M. Carr, Color. Technol., 136, 224 (2020), https://doi.org/10.1111/cote.12456

26 Q. Mohtashim, M. Rigout and S. H. Siddique, Pigment Resin Technol., 49, 431 (2020), https://doi.org/10.1108/PRT-11-2019-0104.

27 Q. Mohtashim and M. Rigout, Mehran Univ. Res. J. Eng. Technol., 38, 421 (2019), https://doi.org/10.22581/muet1982.1902.16

28 Q. Mohtashim and M. Rigout, NED Univ. J. Res., 14, 93 (2017)

${ }^{29}$ K. H. Prabhu and A. S. Bhute, J. Nat. Prod. Plant Resour., 2, 649 (2012)

${ }^{30}$ K. Ramakrishnan, S. R. Selvi and R. Shubha, Indian Chem. Eng., 48, 88 (2006)

31 Tanatex Chem. Prod. Datasheet, Tanatex Chem. B.V., Netherland

32 D. M. Soignet, R. J. Berni and R. R. Benerito, J. Appl. Polym. Sci., 20, 2483 (1976)

${ }_{33}$ Q. Mohtashim and M. Rigout, AATCC J. Res., 6, 1 (2019), https://doi.org/10.14504/ajr.6.4.1

34 J. Walton, P. Wincott, N. Fairley and A. Carrick, "Peak Fitting with CasaXPS: A Casa Pocket Book", Accolyte Science, Knutsford, UK, 2010

35 G. Soliman, C. M. Carr, C. C. Jones and M. Rigout, Dyes Pigm., $\quad$ 96, $25 \quad$ (2013), https://doi.org/10.1016/j.dyepig.2012.06.021

36 J. Buchert, J. Pere, L.-S. Johansson and J. M. Campbell, Text. Res. J., 71, 626 (2001), https://doi.org/10.1177/004051750107100710 